DOI: https://doi.org/10.24867/13AM05Gasic

\title{
ODRŽIVA TRANZICIJA SISTEMA DALJINSKOG GREJANjA - PRIMERI DOBRE PRAKSE
}

\section{SUSTAINABLE TRANSITION OF DISTRICT HEATING SYSTEMS - EXAMPLE OF GOOD PRACTICE}

\begin{abstract}
Oblast- MAŠINSTVO
Kratak sadržaj - U radu je opisan princip rada daljinskog grijanja, podjela sistema daljinskog grijanja kao $i$ značaj elastičnosti sistema na uspješnost implementacije sistema. Takođe predočene su prednosti $i$ potrebe za skladištenje energije, kao i problem velike emisije gasova staklene bašte $u$ atmosferu te $i$ rješenje problema uvođenjem poreza na ugljenik.
\end{abstract}

Keywords: Grejanje, skladištenje energije, porez na uglenik.

\begin{abstract}
The paper describes the working principle of district heating, the division of the district heating system as well as the importance of the elasticity of the system on the success of the system implementation. The advantages and needs for energy storage are also presented, as well as the problem of high greenhouse gas emissions into the atmosphere and the solution to the problem by introducing a carbon tax.
\end{abstract}

Keywords: Heating, Energy storage, Carbon tax.

\section{UVOD}

Trenutno se u svijetu ne mijenja samo klima i politička scena, nego i svjesnost i očekivanja korisnika energije, te njihove potrebe postaju zahtjevnije. Da bi se opravdala očekivanja potrebno je dizajnirati energetski sistem tako da se može nositi ne samo sa očekivanim smetnjama nego da i ukoliko te smetnje dovedu do kolapsa sistema, isti može u najkraćem roku da se vrati u normalno stanje rada. Jedan od primjera energetskog sistema čija infrastruktura može pružiti inzvanrednu otpornost $u$ odnosu na pojedinačni sistem jeste sistem grijanja na daljinu.

Sistem za daljinsko grijanje je veoma energetski efikasan, zato što se ostvaruje istovremena proizvodnja toplotne i električne energije u kombinovanim termoelektranama. Često se ističe da upotreba obnovljivih izvora energije zahtijeva značajno skladištenje električne energije.

Čista energija nastala iz obnovljivih izbora energije, ne zagađuje životnu sredinu i ne dovodi do porasta srednje globalne temperature.

\footnotetext{
NAPOMENA:

Ovaj rad proistekao je iz master rada čiji mentor je bio doc. dr Aleksandar Anđelković.
}

\section{GRIJANJE NA DALJINU}

Sistem daljinskog grijanja je sistem gdje je moguće obezbijediti potrebnu energiju domaćinstvima ili industrijskim objektima iz jednog centra. Taj centar može biti gradski sistem ili sistem koji će snabdijevati toplotnom energijom više naseljenih mjesta, to jeste regiju, ili čitavu državu. Daljinsko grijanje funkcioniše tako što toplana proizvodi toplotu i transportuje je kroz mrežu daljinskog grijanja do potrošača. Topla voda se u domaćinstvima koristi za grijanje prostorija, kao i za proizvodnju tople sanitarne vode. Sanitarna voda se zagrijava u izmjenjivaču toplote, gdje topla voda svoju toplotu prenosi na vodu koja izlazi iz slavina [3].

\subsection{VRSTE SISTEMA ZA GRIJANJE NA DALJINU}

Sistem daljinskog grijanja može obuhvatati velika područja, primjer je sistem koji pokriva šire područje Kopenhagena, ali isto tako i manja područja kao što su sela koja imaju manji broj kuća. Instalisana snaga sistema za daljinsko grijanje varira u zavisnosti od veličine područja koje obuhvata. U velikim sistemima mreža sistema može se sastojati od magistralne mreže koja prenosi toplotu na velike udaljenosti, pri visokim temperaturama i pritiscima. Pored velikih sistema daljinskog grijanja postoje jos mali i mikto sistemi [3].

\subsubsection{MALI SISTEMI DALJINSKOG GRIJANJA}

Mali sistemi daljinskog grijanja predstavljaju lokalne kocepte za snabdijevanje toplotom domaćinstava i malih i srednjih preduzeća iz obnovljivih izvora energije. U nekim slučajevima mali sitetmi mogu biti povezani sa velikim sistemima daljinskog grijanja, ali opšta ideja je da mali sistemi imaju individualnu distrubutivnu mrežu na koju je povezan relativno mali broj potrošača. Ovi koncepti se često realizuju u manjim gradovima ili selima. $\mathrm{U}$ tu svrhu se često koriste toplotni izvori kao što su solarna energija, biomasa, toplota iz industrijskih procesa itd [3].

\subsubsection{MIKRO SISTEMI GRIJANJA NA DALJINU}

Mikro sistemi daljinskog grijanja uglavnom snabdijevaju mali broj potrošača, na primjer dva ili deset. Prednost ovih sistema je to što se mogu znatno brže i jednostavnije izgraditi, zbog malog broja potrošča i jednostavnijih procedura.

Nezavisno o veličini distibutivne mreže važno je da da se tokom planiranja sistema mreža ne predimenzioniše, zato što veće dimenzije mreže uzrokuju veće toplotne gubitke i veće investicione troškove [3]. 


\section{ELASTIČNOST}

Elastičnost se može definisati kao sposobnost neprilagođavanja promjeni. U odnosu na infrastrukturne sisteme, pojam elestičan, odnosi se na sposobnost sistema i njegovih podsistema da apsorbuju smetnje i zadrže svoju osnovnu funkciju i kapacitet tokom i nakon poremećaja. Smetnje mogu nastati iz različitih razloga, a najčešće se smatra da su poremećaji klime i zlonamjerni fizički ili internet napadi, ili oštećenja komponenata. Elastičnost je usko povezan pojam sa fleksibilnošću i robusnošću, gdje se feksibilnost odnosi na situacije kada je neohodno prilagođavanje manjim promjenama, dok je robusnost odlika sistema da se nosi sa neočekivanim događajima. Otpornost podrazumijevana fleksibilnosti i robusnost i dodaje mogućnost sistemu da se mijenja iz jednog stanja u drugo da bi se izborio sa poremećajima.

Fleksibilnost bi mogla biti, na primjer, sposobnost sistema da se snađe sa promjenljivim zahtjevima izvan projektnih uslova ili sa primjenom vremenskih uslova. Robusnost je spospobnost sistema da pruži svoju osnovnu uslugu čak i u slučaju elektičnog kvara na strani potrošača. Grafičko objšnjene o reakcijskim razlikama izmedju tradicionalnog i elastičnog sistema, prikazano je na slici 1. Poremećaj bi mogao biti kvar glavne toplane, gdje je tradicionalni sistem sa jednim postrojenjem, te bi se sistem srušio, ali otporniji sistem koji ima više postrojenja za grijanje i skladištenje toplote ne bi. Ovi sistemi održavaju veću funkcionalnost i imaju brži oporavak [6].

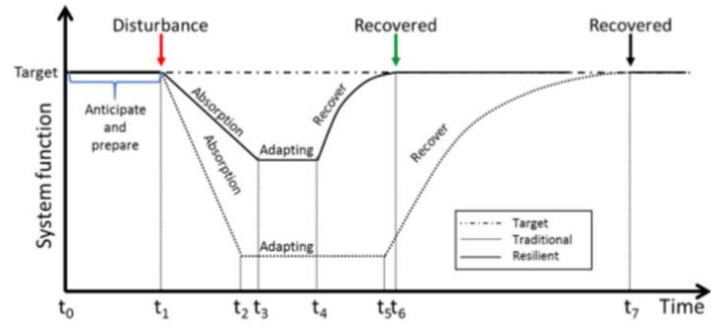

Slika1. Prikaz sposobnosti tradicionalnog i elastičnog sistema da reaguju na poremećaje.

\subsection{PRIMJER DALJINSKOG GRIJANJA NA GRENLANDU}

Važnost elastičnosti zavisi od lokacije i funkcije svake od lokacija. U udaljenim arktičkim regijama, isključeni iz električne i plinske mreže izbjegavaju lokalne resurse. To je slučaj u Kuanakuu, koji je poznat još pod nazivom Thule. Kuanaku je američka vazduhoplovna baza, i dom za 656 ljudi. Kuanaku je osnovan 1952.godine za smještaj domaćeg stanovništva i vazduhoplovne baze. Infrastruktira je napravljena kao kampus, što je pružalo dobru priliku za optimizaciju naselja i sinergiju različitih sistema. Energetska efikasnost je ključni parametar za preživljavanje, gdje je Kuanak smješten i 9 mjeseci godišnje je pod ledom. Da bi se lokalnom stanovništvu osigurala efikasnost vazduhoplovne baze, i bezbijedno životno oktuženje energetska infrastruktura mora biti funkcionalna sve vrijeme i mora raditi sa maksimalnom efikasnošću goriva, kako bi se smanjili troškovi goriva i rizik od nestašice goriva [6].

Kombinvani sistem grijanja i napajanja ima efikasnost goriva od $80-85 \%$. U slučaju kotlova samo za proizvodnju električne energije i koji se koriste za toplotnu energiju, zajednička efikasnost bi bila samo $55 \%$.

\section{SKLADIŠTENJE ENERGIJE}

Skladištenje energije predstavlja bitan segment svih fizičkih procesa i omogućava upravljanje energijom. Svaka tehnologija za skladištenje električne energije se zasniva na transformaciji energije iz jednog oblika u drugi. Energija se skladišti u intervalima kada proizvodnja energije nadmašuje njenu potrošnju, a skladištene rezerve se koriste kada potrošnja energije nadmašuje njenu proizvodnju. Zajednička karakteristika svih tehnologija za skladištenje energije je relativno visok stepen početne investicije, ali i njihova kasnija niska operativna cijena. To je razlog zbog čega se danas velika pažnja posvećuje razvoju i upotrebi ovakvih sistema [2].

\subsection{ZNAČAJ SKLADIŠTENJA ENERGIJE}

Godine 2015. 195 država koje su odgovorne za 99,75 \% emisija gasova staklene bašte u svijetu potpisalo je Pariški sporazum. Države koje su potpisale sporazum obvezale su se na to da će u tekućem vijeku ograničiti rast prosječne temperature u svijetu na nivo koji je znatno niži od $2{ }^{\circ} \mathrm{C}$ iznad nivoa u predindustrijskom razdoblju, uz ciljno ograničenje od $1,5^{\circ} \mathrm{C}$. Evropska Unija je takođe utvrdila sopstvnene ciljne vrijednosti u cilju smanjenja emisija gasova staklene bašte, što je prikazano na slici 2. Sa slike broj 8 , može da se vidi da je ciljna vrijednost emisije gasova staklene bašte za 2020.godinu $20 \%$ manja u odnosu na 1990. godinu, dok je za 2030.godinu cilj da se emisije smanje za $40 \%$ ukupno, za 2050.godinu cilj je smanjenje emisija gasova staklene bašte za $80 \%$ [4].

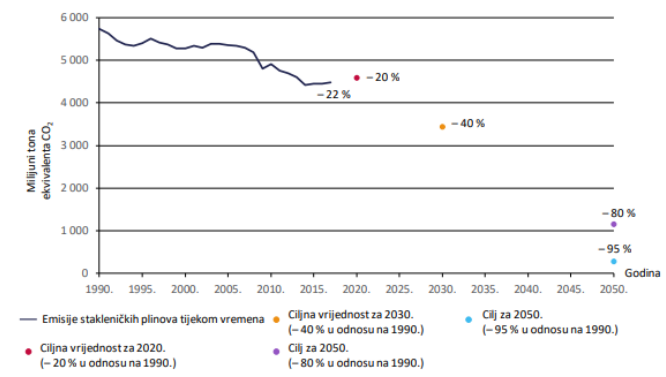

Slika 2. . Trendovi kretanja i ciljne vrijednosti emisija gasova staklene bašte

\subsection{VRSTE I ELEMENTI ZA SKLADIŠTENJE ENERGIJE}

Najčešće korišćena metoda podjele spremnika za skladištenje energije proističe iz njegove definicije kao tijela koje skladišti neki oblik unutrašnje energije. Prema ovom kriterijumu, razlikuju se:

-spremnici mehaničke energije

-spremnici elektromegnetne potencijalne energije,

- spremnici elektrohemijske energije,

-spremnici unutrašnje kalorične (termalne) energije, hemijske ili elektrohemijske energije.

Ako se prethodno datom kriterijumu pridruže i odgovarajuće tehnologije, slijedi da spremnike (električne) energije možemo dalje podijeliti na hidropumpne sisteme PHS ( Pumped Hydro Systems), zamajce spremnike sabijenog vazduha, CAES (Compressed Air Energy Storage), spiralne opruge, kapacitivne spremnike, induktivne spremnike SMES (Super Magnetic Energy Storage), spremnike toplotne energije, akumulatore i baterije, vodonik i solarna goriva, kao što je prikazano na slici 3 [1]. 


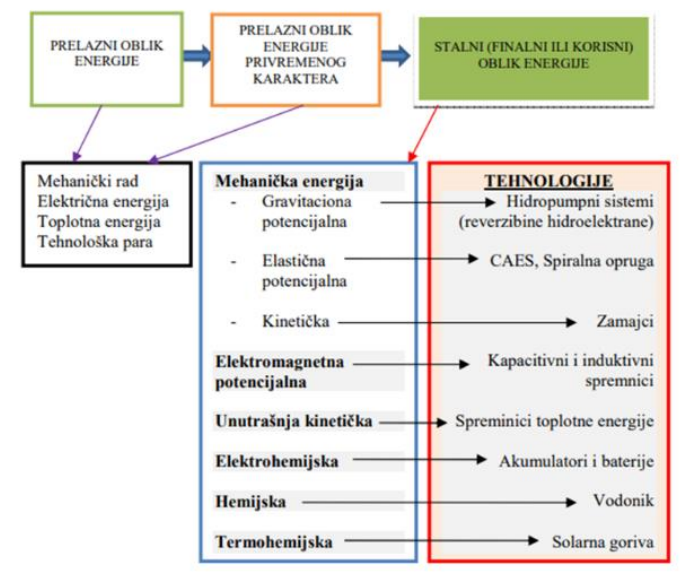

Slika 3. . Energetska kategorizacija spremnika energije

\section{POREZ NA UGLJENIK}

Kad je riječ o ekološkom porezu, osnovica poreza je fizička jedinica za koju je dokazan specifičan negativan uticaj na okolinu kada je upotrijebljena ili emitovana. Ako je osnovica za porez količina $\mathrm{CO}_{2}$ koja se oslobodi pri sagorijevanju jedinice goriva, takav porez zovemo porez na ugljenik. Ako je osnovica poreza količina energije koja se dobije pri sagorijevanju jedinice goriva, takav porez zovemo energetski porez [5]. Države u kojima se porez na $\mathrm{CO}_{2}$ već primjenjuje uglavnom su kao osnovicu za porez izabrale kilogram ili tonu emisije $\mathrm{CO}_{2}$ koja se oslobađa pri sagorijevanju jedinice goriva (Švedska, Norveška, Danska, Finska) ili osnovicu za porez čini količina ugljenika u predmetu oporezivanja i količina energije koja se oslobodi pri sagorijevanju predmeta oporezivanja (Holandija, 50/50).. Zna se da su najviše za ugljenik i najniže za prirodni gas. Zbog toga nastaju razlike $u$ oporezivanju pojedinih energenata, što je i normalno, jer je cilj oporezivanja smanjenje emisije odnosno prebacivanje potrošnje $\mathrm{s}$ emisijski intenzivnih goriva na relativno manje emisijski intenzivna goriva.

\subsection{PRIMJER PRIMJENE POREZA NA UGLJENIK U FRANCUSKOJ}

Dosadašnja saznanja i ispitvinja pokazuju da je neophodno da se emisija $\mathrm{CO}_{2}$ smanji za 50 ili $55 \%$ do 2030. godine [9]. Naravno, najlakši način da se to postigne jeste da se uvede porez na ugljenik, to jeste ako bi emisije ugljenika bile skuplje, upotreba fosilnih goriva bi se značajno smanjila. Nedostatak je to što bi veće cijene ugljenika značine ogroman udar na životni standard i to posebno domaćinstvima sa manjim primanjima. To je zato što siromašnije stanovništvo već troši više novca na grijanje i gorivo sa većim sadžajem ugljenika.

Kada je vlada Francuske pokušala da poveća cijene poreza na ugljenik, za gorivo i grijanje, reakcija pokreta Žuti prsluci je bila veoma burna . Problem prevelike emisije $\mathrm{CO}_{2}$ mora biti riješen a to pogađa najugroženije stanovništvto.. Ovdje je potrebno pronaći kompromis, što su francuski ekonomisti i uradili. Poenta je bila da dokazu da je stanovništvu bolje sa porezom na ugljenik nego bez. Ovakav sistem bi radio na sljedeći način: kada vozač natoči gorivo u automobil na računu postoje dvije stavke - prva je cijena goriva a druga je porez na ugljenik. Ova druga stavka bi trebala, prema mišljenju ekonomista, da ohrabri stanovništvo da koriste manje fosilnih goriva koji doprinose klimatskim promjenama [9]. Rješenje ovog priblema bi moglo biti to da novac od poreza na ugljenik ne odlazi u budžet države, nego da se vraća stanovništvu. Kao zaključak ovog primjera vidi se da je za smanjenje emisija $\mathrm{CO}_{2}$ potrebna saradnja između države i stanovnika, te da se pronađe način da porez na ugljenik bude fer.

\section{ZAKLJUČAK}

Podaci da je tačnost isporuke toplotne energije za daljinsko grijanje u Helsinkiju, Stotholmu i Kopenhagenu uvijek iznad 99,9\% godišnje, svjedoče o pouzdanosti sistema daljinskog grijanja. Sistemi u ovih gradovima pokrivaju veliku većinu datog grada, stotine hiljada zgrada su u funkciji su više od pola vijeka. Isto iskustvo je slučaj i u drugim sistemima širom Skandinavije. Pitanje skladištenja energije je od suštinske važnosti kada se raspravlja o načinu primjene velike integracije obnovljive energije kako u trenutni sistem, tako i u budućem prelazu na $100 \%$ snabdijevanje obnovljivom energijom. Fokus samo na podsektor električne energije - kao što se vidi iz pristupa pametnoj mreži - obično dovodi do prijedloga koji su prvenstveno usredsređeni na tehnologije skladištenja električne energije u kombinaciji sa fleksibilnim zahtevima za električnom energijom i prenosnim linijama do susednih zemalja.

\section{LITERATURA}

[1] Zdravko Milovanović, Ljubiša Papić, Aleksandar Milašinović, Darko Knežević, Svetlana DumonjićMilovanović, Održivo planiranje energije: Tehnologije i energetska efikasnost, Banja Luka 2018.

Dostupno na https://www.researchgate.net/publication/327201347_Sad rzaj

[2] Skladištenje energije - Jedan od posljednjih koraka u zaustavljanju klimatskih promena, dostupno na :

https://klima101.rs/skladistenje-energije/

[3] Modularni sistem daljinskog grijanja i hlađenja, dostupno na:

https://www.coolheating.eu/images/downloads/D4.1_Han dbook_RS.pdf

[4] Potpora EU za skladištenje energije, dostupno na:

https://www.eca.europa.eu/lists/ecadocuments/brp_energy /brp_energy_hr.pdf

[5] dr Renata Slabe-Erker, Porez na ugljenik kao mjera smanjenja emisije ugljen dioksida, Institut za ekonomska istraživanja, Ljubljana

[6] District Energy - the resilient energy infrastructure, Thermal Energy Systems Resilience in

Cold/Arctic Climates Consultation Forum 22nd - 23rd of January 2020 Fairbanks, Alaska, USA

\section{Kratka biografija}

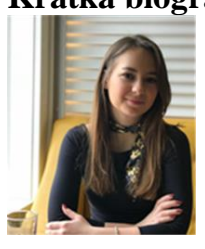

Dragana Gašić, rođena u Bijeljini, BiH RS 1995. godine. Osnovne studije na Fakultetu tehničkih nauka, Novi Sad, Mašinstvo Energetika i procesna tehnika, završila je 2018. godine.

Email:dragana_gasic@yahoo.com 